\title{
Atividade Residual de Herbicidas Pré-Emergentes Aplicados na Cultura da Soja sobre o Milheto Cultivado em Sucessão ${ }^{1}$
}

\author{
Effect of the Residual Activity of Pre-Emergent Herbicides Applied in Soybean on Pearl Millet \\ Cultivated in Succession
}

\author{
DAN, H.A. ${ }^{2}$, DAN, L.G.M. ${ }^{3}$, BARROSO, A.L.L. ${ }^{4}$, PROCÓPIO, S.O. ${ }^{5}$, OLIVEIRA JR., R.S. ${ }^{6}$, \\ ASSIS, R.L. ${ }^{7}$, SILVA, A.G. ${ }^{4}$ e FELDKIRCHER, C. ${ }^{8}$
}

\begin{abstract}
RESUMO - O objetivo deste estudo foi avaliar a atividade residual de herbicidas utilizados no manejo de plantas daninhas em pré-emergência da cultura da soja, bem como verificar seus efeitos sobre o milheto cultivado em sucessão. Utilizaram-se parcelas de $80 \mathrm{~m}^{2}$, em delineamento de blocos casualizados, com quatro repetições, em esquema de parcelas subdivididas $5 \times 4$, correspondendo à aplicação dos herbicidas imazaquin $\left(0,160 \mathrm{~kg} \mathrm{ha}^{-1}\right)$, diclosulam $\left(0,035 \mathrm{~kg} \mathrm{ha}^{-1}\right)$, sulfentrazone $\left(0,600 \mathrm{~kg} \mathrm{ha}^{-1}\right)$ e flumioxazin $\left(0,050 \mathrm{~kg} \mathrm{ha}^{-1}\right)$ e uma testemunha, aplicados logo após a semeadura do cultivar de soja Msoy-6101. Nas subparcelas, realizou-se a semeadura do milheto, cultivar ADR-7010, em quatro periodos, correspondendo a 0, 40, 80 e 120 dias após a aplicação dos herbicidas (DAA). Durante a condução do ensaio, foram determinados os niveis de intoxicação, estande, altura e massa seca da parte aérea das plantas de milheto. No final do ciclo foi avaliado o rendimento de grãos da cultura. $\mathrm{O}$ híbrido de milheto ADR-7010 apresentou elevada sensibilidade com relação à atividade residual dos herbicidas sulfentrazone, diclosulam e imazaquin quando cultivado logo após a aplicação destes. A bioatividade dos herbicidas imazaquin, diclosulam e flumioxazin não foi suficiente para alterar o rendimento de grãos do milheto cultivado em sucessão à soja (120 DAA), mostrando que esse intervalo de tempo é suficiente para dissipação desses herbicidas. Dos herbicidas pré-emergentes avaliados, o sulfentrazone apresentou maior atividade residual, influenciado negativamente o rendimento da cultura durante o intervalo de tempo estudado.
\end{abstract}

Palavras-chave: carryover, sulfentrazone, diclosulam, imazaquin, flumioxazin, Pennisetum glaucum.

\begin{abstract}
The objective of this study was to evaluate the persistence of herbicides applied in pre-emergence in soybean crop and the effects of these herbicides on pearl millet grown in succession. The herbicides imazaquin $\left(0.160 \mathrm{~kg} \mathrm{ha} \mathrm{a}^{-1}\right)$, diclosulam $\left(0.035 \mathrm{~kg} \mathrm{ha}^{-1}\right)$, sulfentrazone $\left(0.600 \mathrm{~kg} \mathrm{ha} \mathrm{a}^{-1}\right)$, and fumioxazin $(0.050 \mathrm{~kg} \mathrm{ha}-1)$ were used immediately after sowing of soybean Msoy-6101, in plots of $80 \mathrm{~m}^{2}$, divided into sub-plots of $20 \mathrm{~m}^{2}(5 \times 4 \mathrm{~m})$. A randomized block design with four replications was used in a split-plot scheme $5 \times 4$. In the sub-plots, pearl millet hybrid ADR-7010 was sown in four periods after herbicide application, corresponding to 0,40,80 and 120 days after herbicide application (DAA). Pear millet injury, stand, height and dry biomass of the plant were evaluated at 7 , 15 , and 28 days after emergence; crop grain yield was evaluated at the end of the cycle. Pearl millet hybrid ADR-7010 showed high sensitivity to the residual activity of sulfentrazone, imazaquin, and diclosulam when grown immediately after herbicide application. The bioactivity of imazaquin, diclosulam, and flumioxazin was not sufficient to affect grain yield of millet grown after soybean (120 DAA), suggesting that this interval is sufficiently long for dissipation of these herbicides. Among the pre-emergent herbicides, sulfentrazone showed longer residual activity, negatively influencing the crop's yield during the time interval studied.
\end{abstract}

Keywords: carryover, sulfentrazone, diclosulam, imazaquim, flumioxazin, Pennisetum glaucum.

1 Recebido para publicação em 26.5.2010 e na forma revisada em 6.5.2011.

2 Discente do Programa de Pós-Graduação em Agronomia, Universidade Estadual de Maringá - UEM/NAPD, Av. Colombo 5790, 87020-900 Maringá-PR, <halmeidadan@gmail.com>; ${ }^{3}$ Mestranda, Programa de Pós-Graduação em Agronomia, Universidade Estadual de Maringá - UEM; ${ }^{4}$ Professores da Faculdade de Agronomia, FESURV, Caixa Postal 10475.901-970 Rio Verde-GO; ${ }^{5}$ Pesquisador, Embrapa Soja, 86001-970 Londrina-PR; ${ }^{6}$ Professor do Dep. de Agronomia - UEM/NAPD; 7 Professor do Instituto Federal Goiano - Campus Iporá, Rodovia GO 060, Km 01, 76200-000 Iporá-GO; ${ }^{8}$ Graduando em Agronomia, FESURV.

Planta Daninha, Viçosa-MG, v. 29, n. 2, p. 437-445, 2011 


\section{INTRODUÇÃO}

Devido à sua grande adaptação e difusão no bioma dos cerrados, o milheto vem ganhando destaque nos últimos anos, especialmente após o lançamento de híbridos de alto potencial produtivo, oriundos do melhoramento genético (Dan et al., 2010). Além disso, a cultura apresenta boa produção de palhada, constituindose em importante opção para o sistema de plantio direto e na produção de forragem quando plantado em sucessão (Torres et al., 2008). Esses fatos, em conjunto, possibilitaram que a cultura passasse a apresentar valor econômico expressivo.

A sucessão de culturas vem sendo muito utilizada no Brasil, porém pouco tem sido feito a fim de se avaliar o efeito residual dos herbicidas utilizados na cultura da soja sobre culturas cultivadas em sequência, como o milheto. Sabe-se que a atividade residual dessas moléculas apresenta grande complexidade, sendo os efeitos negativos da atividade residual de herbicidas aplicados à cultura da soja sobre culturas em sucessão relatados por Gazziero et al. (1997), Ulbrich et al. (1998, 2005), Brighenti et al. (2002) e Artuzi \& Contiero (2006).

Dentre os herbicidas utilizados em préemergência na cultura da soja, destacam-se imazaquin, diclosulam, sulfentrazone e flumioxazin. O imazaquin possui meia-vida média no solo de 60 dias, mas sua atividade residual ainda pode ser observada, em alguns casos, de 90 a 180 dias após a aplicação (Silva et al., 1998). A variação na persistência pode ocorrer em função de propriedades do solo, como o pH, umidade, teor de matéria orgânica e textura (Baughman \& Shaw, 1996).

O diclosulam apresenta meia-vida $\left(t_{1 / 2}\right)$ de 67 dias em áreas cultivadas em sistema de plantio direto e de 87 dias em solos cultivados convencionalmente (Lavorenti et al., 2003). De acordo com Yoder et al. (2000), em solos paranaenses, argentinos e americanos, a meia-vida desse herbicida foi de 16 a 54 dias. Contudo, dose equivalente a 33,6 $\mathrm{g} \mathrm{ha}^{-1}$ de diclosulam foi suficiente para reduzir o estande da cultura do girassol semeado aos 90 dias após a sua aplicação na cultura da soja (Brighenti et al., 2002).
O sulfentrazone pode persistir no solo por um período superior a 539 dias (Blanco \& Velini, 2005). Todavia, apresenta bioatividade mais intensa em solos de textura argilosa ou contendo elevados teores de matéria orgânica (Reddy \& Locke, 1998), onde é sorvido eficientemente e dessorvido lentamente. A atividade microbiológica é a grande responsável pela degradação do sulfentrazone (Cobucci \& Portela, 2001). Resíduos desse herbicida (600 $\mathrm{g} \mathrm{ha}^{-1}$ ) causaram redução no rendimento da cultura do milheto cultivado aos 157 dias após a sua aplicação (Blanco \& Velini, 2005).

O flumioxazin é um herbicida adsorvido pelos coloides do solo, principalmente pela matéria orgânica (Ferrell et al., 2005), com lixiviação reduzida em razão de não apresentar dissociação em água. Apresenta rápida dissipação no solo, com meia-vida variando de 10 a 25 dias (Ferrell et al., 2005). Alister et al. (2008) verificaram que apenas $24 \%$ do flumiozaxin foi encontrado aos 90 dias após a sua aplicação. Lima et al. (1999) relatam que residuos de flumioxazin no solo afetaram seriamente o acúmulo de matéria seca em plantas de pepino. Wilcut et al. (2003) constataram que a espécie Arachis hypogaea apresentou crescimento reduzido ao ser implantada cinco semanas após a aplicação de $20 \mathrm{~g} \mathrm{ha}^{-1}$ de flumioxazin.

Visando à continuidade da expansão da cultura do milheto no País, é de fundamental importância a identificação de possiveis efeitos causados por resíduos de herbicidas utilizados em culturas antecessoras, como a soja. Nesse contexto, o objetivo do presente trabalho foi avaliar a atividade residual de herbicidas utilizados na soja, aplicados em préemergência, e seus efeitos sobre o milheto cultivado em sucessão.

\section{MATERIAL E MÉTODOS}

Os experimentos foram conduzidos em campo e casa de vegetação, no campus da FESURV, em Rio Verde-GO (17 $47^{\circ} 03^{\prime \prime} \mathrm{S}$, $50^{\circ} 57^{\prime} 32^{\prime \prime} \mathrm{W}$, a 743 de altitude), durante o período de novembro de 2008 a julho de 2009.

Os experimentos foram implantados em um Latossolo Vermelho distroférrico, textura 
argilosa, com as seguintes características químicas e físicas na profundidade de $0-20 \mathrm{~cm}$ : $\mathrm{pH}$ em $\mathrm{CaCl}_{2}: 4,8$; Ca: $1,83 \mathrm{cmol}_{\mathrm{c}} \mathrm{dm}^{-3}$; $\mathrm{Mg}$ : 1,07 $\mathrm{cmol}_{\mathrm{c}} \mathrm{dm}^{-3}$; $\mathrm{Al}: 0,27 \mathrm{cmol}_{\mathrm{c}} \mathrm{dm}^{-3} ; \mathrm{H}+\mathrm{Al}$ : $5,6 \mathrm{cmol}_{\mathrm{c}} \mathrm{dm}^{-3} ; \mathrm{K}: 213 \mathrm{mg} \mathrm{dm}^{-3} ; \mathrm{P}: 10,56 \mathrm{mg} \mathrm{dm}^{-3}$; CTC: $10,16 \mathrm{cmol}_{\mathrm{c}} \mathrm{dm}^{-3}$; MO: $28,84 \mathrm{~g} \mathrm{~kg}^{1}$; argila: $510 \mathrm{~g} \mathrm{~kg}^{-1}$; silte: $50 \mathrm{~g} \mathrm{~kg}^{-1}$; e areia: $440 \mathrm{~g} \mathrm{~kg}^{-1}$.

Quinze dias antes da semeadura da soja, foi realizado o manejo químico das plantas daninhas presentes na área, com a utilização de $1,8 \mathrm{~kg} \mathrm{ha}^{-1}$ de glyphosate $+0,5 \mathrm{~kg} \mathrm{ha}^{-1} \mathrm{de}$ 2,4-D, complementada com aplicação de $0,2 \mathrm{~kg} \mathrm{ha}^{-1}$ de paraquat 48 horas antes da semeadura.

O cultivar de soja M-soy 6101, de ciclo precoce, foi semeado no dia 21 de novembro de 2008, em espaçamento de $0,5 \mathrm{~m}$, de forma mecanizada, obtendo-se uma população final de 230 mil plantas ha ${ }^{-1}$. No momento da semeadura, foi feita uma adubação de base com $80 \mathrm{~kg} \mathrm{ha}^{-1}$ de $\mathrm{P}_{2} \mathrm{O}_{5}$ (superfosfato simples) e $20 \mathrm{~kg} \mathrm{ha}^{-1}$ de $\mathrm{K}_{2} \mathrm{O}$ (cloreto de potássio). Também, realizou-se adubação de cobertura com $30 \mathrm{~kg} \mathrm{ha}^{-1}$ de $\mathrm{K}_{2} \mathrm{O}$ (cloreto de potássio) aos 30 dias após a emergência.

As parcelas foram dimensionadas numa área de $80 \mathrm{~m}^{2}$, que foi subdividida em unidades de $20 \mathrm{~m}^{2}(5 \times 4 \mathrm{~m})$. Foi utilizado delineamento de blocos casualizados, com quatro repetições, em esquema de parcelas subdivididas $5 \times 4$, correspondendo aos herbicidas imazaquin $\left(0,160 \mathrm{~kg} \mathrm{ha}^{-1}\right)$, diclosulam $\left(0,035 \mathrm{~kg} \mathrm{ha}^{-1}\right)$, sulfentrazone $\left(0,600 \mathrm{~kg} \mathrm{ha}^{-1}\right)$ e flumioxazin $\left(0,050 \mathrm{~kg} \mathrm{ha}^{-1}\right)$ e uma testemunha. Na parcela foram alocados os herbicidas aplicados em préemergência, e nas subparcelas foi semeada a cultura do milheto em quatro períodos, correspondendo a 0,40, 80 e 120 dias após a aplicação dos herbicidas.

A aplicação dos tratamentos herbicidas foi realizada utilizando-se um pulverizador costal com pressurização por $\mathrm{CO}_{2}$, munido de barra de $2 \mathrm{~m}$, contendo quatro pontas de pulverização do tipo AI 110-02 (0,5 m entre pontas), com pressão de serviço de $2,5 \mathrm{kgf} \mathrm{cm}^{-2}$, proporcionando volume de calda equivalente a $150 \mathrm{~L} \mathrm{ha}^{-1}$. As condições ambientais no momento da aplicação foram: temperatura média de $27,2{ }^{\circ} \mathrm{C}$, UR média de $79 \%$ e velocidade do vento média de $6,1 \mathrm{~km} \mathrm{~h}^{-1}$. A aplicação foi iniciada às $7 \mathrm{~h} 30$, com término às $7 \mathrm{~h} 54$.
O milheto (híbrido ADR-7010) foi semeado manualmente, mantendo uma população de 140 mil plantas ha-1, em espaçamento de $0,5 \mathrm{~m}$. A semeadura do milheto ocorreu após a retirada dos restos culturais da cultura da soja. Após essa semeadura, foi realizada aplicação de $0,25 \mathrm{~kg} \mathrm{ha}^{-1}$ de paraquat, visando à eliminação das plantas daninhas remanescentes. No momento da semeadura do milheto, realizou-se adubação de $100 \mathrm{~kg} \mathrm{ha}^{-1} \mathrm{da}$ fórmula 04-14-08. Foram realizadas ainda duas adubações de cobertura de $15 \mathrm{~kg} \mathrm{ha}^{-1}$ de nitrogênio (sulfato de amônio), aos 15 e 35 dias após a emergência da cultura (DAE). O controle de plantas daninhas na cultura do milheto foi realizado por meio de capinas manuais.

Durante a condução do ensaio as precipitações ocorreram de forma regular, sem anormalidade, proporcionando um acumulado de $1.356 \mathrm{~mm}$, distribuídos em 10 meses.

Após a emergência do milheto, foram realizadas avaliações de intoxicação aos 7 e 28 DAE, utilizando-se escala percentual de 0 (zero) a $100 \%$, em que 0 (zero) representa ausência de sintomas e 100 a morte de todas as plantas. Aos $30 \mathrm{DAE}$, foi realizada avaliação de estande, por meio da contagem do número de plantas emergidas em $2 \mathrm{~m}$ lineares, localizadas nas linhas centrais da subparcela. Aos 60 DAE, no estádio fenológico denominado "ponto de rolagem", determinou-se o acúmulo de matéria seca da parte aérea. Para isso, foram coletadas 10 plantas de cada parcela, as quais foram posteriormente secas em estufa com circulação forçada de ar a $65^{\circ} \mathrm{C}$, até massa constante, e imediatamente após pesadas em balança analitica.

No final do ciclo da cultura foi avaliada a altura das plantas, utilizando-se trena graduada, sendo referenciada a distância do colo da planta à extremidade final da panícula. A produtividade de grãos foi determinada por meio da colheita manual das espigas presentes em $3 \mathrm{~m}^{2}$ da área útil das subparcelas. Logo após a colheita, o material foi trilhado manualmente, pesado e a umidade dos grãos corrigida para $13 \%$.

Visando eliminar a influência do ambiente nas épocas de condução, os dados de matéria seca da parte aérea, estande, altura de planta e rendimento de grãos foram transformados 
em valores percentuais em relação ao tratamento testemunha, adotando-se para cada época o valor referencial de $100 \%$ (testemunha), sendo em seguida submetidos à análise de variância.

Em todos os ensaios, os resultados foram transformados em $\sqrt{ } \mathrm{x}+1$ para seguir os pressupostos necessários da análise de variância, realizada com o programa estatístico Sisvar. Foram ajustados modelos de regressão das variáveis que apresentaram significância, utilizando-se posteriormente o programa Sigma Plot versão 10.0 na geração das curvas de regressão. Para comparação das equações de regressão, foi utilizado o procedimento descrito em Snedecor \& Cochran (1989).

\section{RESULTADOS E DISCUSSÃO}

Os resultados de intoxicação apresentados pelos herbicidas imazaquin, diclosulam, sulfentrazone e flumioxazin na cultura do milheto estão expressos na Figura 1. Observase que o cultivar ADR-7010 apresentou diferentes níveis de intoxicação, que variaram em função da época de semeadura após a aplicação do herbicida e do tratamento herbicida presente na unidade experimental.

Durante as avaliações visuais realizadas aos 7 DAE (Figura 1A), os maiores niveis de intoxicação $(100 \%)$ foram proporcionados pelo herbicida sulfentrazone em semeadura realizada logo após a sua aplicação (0 DAA). Aos $28 \mathrm{DAE}$, as injúrias promovidas por esse herbicida foram severas a ponto de causar mortalidade das plantas de milheto. Resultados semelhantes foram observados por Blanco \& Velini (2005) na cultura do milheto, com aplicação de $1,2 \mathrm{~kg} \mathrm{ha}^{-1}$ de sulfentrazone em solo de textura média. Os efeitos visuais se apresentaram de forma inversamente proporcional ao período compreendido entre a aplicação de sulfentrazone e a semeadura do milheto, ou seja, com o aumento do tempo de dissipação do herbicida no solo, menores foram os efeitos na planta. No entanto, mesmo aos 120 DAA constatou-se $36,5 \%$ de intoxicação nas avaliações realizadas aos 28 DAA (Figura 1B), indicando a grande sensibilidade que a espécie apresenta ao referido herbicida.

As plantas de milheto cultivadas na área tratada com flumioxazin mostraram sinais de intoxicação evidentes nas semeaduras que ocorreram aos 0 e 40 DAA. Durante esses períodos, os sintomas foram mais pronunciados nas avaliações aos 7 DAE (Figura 1A), com ligeira recuperação dos sintomas aos 28 DAE. Semeadura realizada em períodos superiores a 80 DAA não apresentou efeito evidente de intoxicação, que se deve à baixa persistência do flumioxazin no solo. Para Ferrell et al. (2005), esse fato ocorre em função da elevada taxa de degradação microbiana e da rápida adsorção desse herbicida no complexo orgânico do solo, onde cerca de $80 \%$ das moléculas do herbicida se apresentam sorvidas em apenas 72 horas.

Dos herbicidas inibidores da enzima acetolactato sintase (ALS), a atividade residual
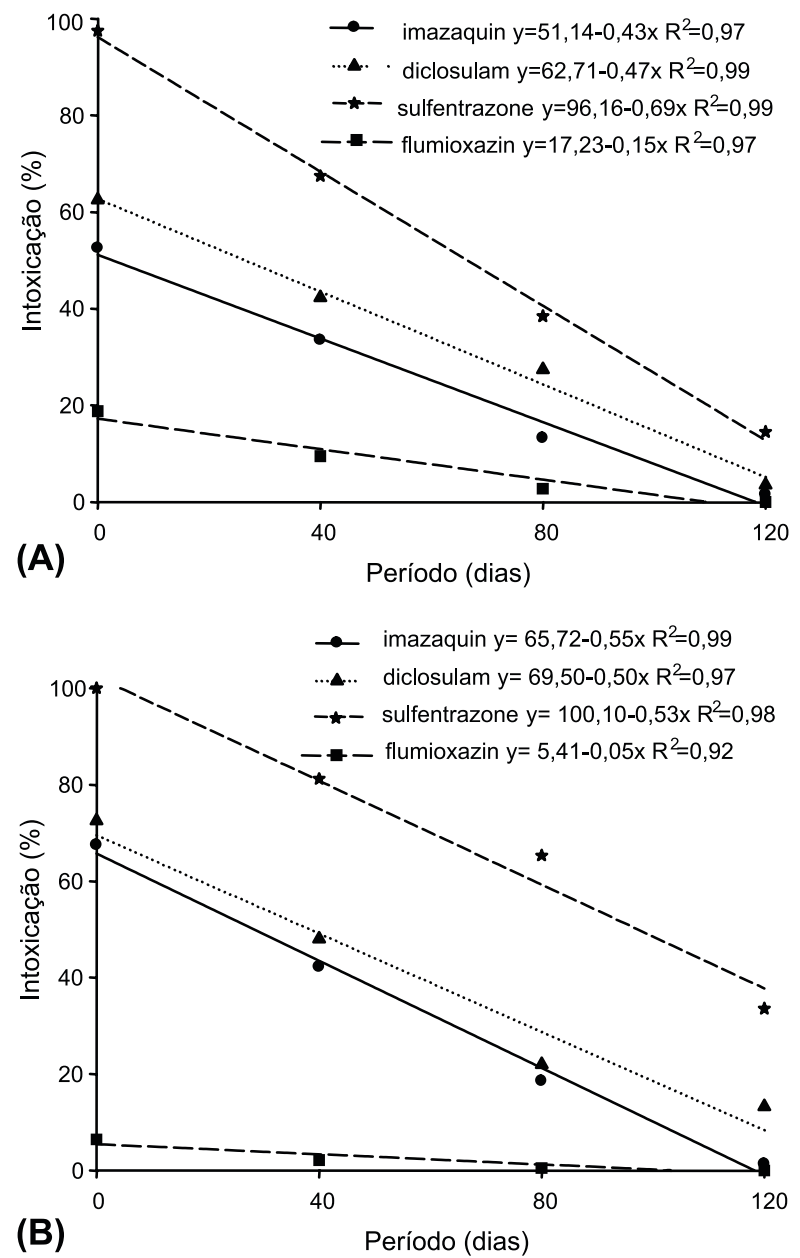

Figura 1 - Intoxicação de plantas de milheto aos 7 (A) e 28 (B) dias após a emergência, cultivadas em solo após a aplicação de herbicidas na cultura da soja, em diferentes épocas de semeadura. 
do diclosulam apresentou maior potencial de intoxicação nas plantas de milheto durante todo o intervalo de avaliação. Observou-se clorose internerval e grande atraso no crescimento das plantas de milheto. Sintomatologia semelhante foi observada por Ulbrich et al. (2005) e Artuzi \& Contiero (2006), ao avaliarem os efeitos de imidazolinonas na cultura do milho. Comparando os coeficientes angulares dos modelos lineares ajustados aos $28 \mathrm{DAE}$ (Figura 1B), observa-se que a redução da porcentagem de intoxicação está diretamente relacionada com o intervalo de tempo entre a aplicação dos herbicidas em pré-emergência e a semeadura do milheto. Com relação a essa variável, a redução na intoxicação foi de 0,55 e $0,50 \%$ para imazaquin e diclosulam, respectivamente, em função do incremento de cada dia entre o intervalo da aplicação e a semeadura da cultura do milheto. Depois da colheita da soja, que ocorreu aos 120 dias após a aplicação dos herbicidas, plantas de milheto semeadas sobre as unidades tratadas com diclosulam apresentaram leve clorose (intoxicação de 9,5\%). Lavorenti et al. (2003) consideram o diclosulam um herbicida de baixa persistência no solo (meia-vida de 67 a 87 dias em plantio convencional e direto, respectivamente). No entanto, algumas espécies podem apresentar maior sensibilidade a esse herbicida, como relatado por Brighenti et al. (2002). Estes autores observaram severa redução no estande e rendimento de grãos em plantas de girassol aos 90 dias após a aplicação de $32 \mathrm{~g} \mathrm{ha}^{-1}$ de diclosulam, em Latossolo Vermelho distroférrico de textura argilosa.
Além dos sintomas de intoxicação visual observados, outro efeito presenciado foi a considerável redução na população de plantas de milheto na semeadura realizada logo após a aplicação dos herbicidas (O DAA), fato esse observado na avaliação realizada aos $30 \mathrm{DAE}$ (Tabela 1). Nesse período, ocorreram reduções de 37,43 e $100 \%$ no estande com a aplicação de imazaquin, diclosulam e sulfentrazone, respectivamente. Durante esse período, o flumioxazin não diferiu da testemunha. Os efeitos do sulfentrazone persistiram durante os períodos de 40 e 80 DAA, quando se obtiveram, respectivamente, 82 e $78 \%$ de redução de estande. Semelhantes resultados foram observados por Artuzi \& Contiero (2006), que constataram redução significativa da população de plantas de milho semeadas logo após a aplicação de diclosulam e sulfentrazone.

Ao analisar os percentuais de acúmulo da matéria seca da parte aérea das plantas de milheto (Figura 2A), constata-se que as maiores reduções foram observadas em semeaduras realizadas no tempo zero (0 DAA). Nessa data de semeadura, todos os herbicidas apresentaram efeitos sobre o acúmulo de matéria seca. Maiores reduções foram observadas nos tratamentos sulfentrazone, diclosulam e imazaquin, os quais causaram 99, 62 e 41\% de redução na matéria seca da parte aérea, respectivamente, quando comparados com a testemunha. Dentro dos períodos de tempo, observa-se que sulfentrazone foi o herbicida com maior capacidade de reduzir o acúmulo de matéria seca na cultura do milheto. Mesmo

Tabela 1 - Porcentagem de redução do estande de plantas de milheto aos 30 dias após a emergência, cultivadas em solo após a aplicação de herbicidas na cultura da soja, em diferentes épocas de semeadura

\begin{tabular}{|c|c|c|c|c|c|}
\hline \multirow{3}{*}{ Tratamento } & \multirow{3}{*}{$\begin{array}{c}\text { Dose } \\
\left(\mathrm{kg} \text { de i.a. } \mathrm{ha}^{-1}\right)\end{array}$} & \multicolumn{4}{|c|}{ Período entre a aplicação e a semeadura do milheto } \\
\hline & & 0 DAA & 40 DAA & $80 \mathrm{DAA}$ & 120 DAA \\
\hline & & \multicolumn{4}{|c|}{ Redução do estande (\%) } \\
\hline testemunha & - & $0,0 \mathrm{cA}$ & $0,0 \mathrm{dA}$ & $0,0 \mathrm{bA}$ & $0,0 \mathrm{aA}$ \\
\hline imazaquin & 0,161 & $37,5 \mathrm{bA}$ & $17,3 \mathrm{cB}$ & $0,0 \mathrm{bC}$ & $0,0 \mathrm{aC}$ \\
\hline diclosulam & 0,035 & $43,9 \mathrm{bA}$ & $32,1 \mathrm{bB}$ & $1,5 \mathrm{bC}$ & $0,0 \mathrm{aC}$ \\
\hline sulfentrazone & 0,600 & $100,0 \mathrm{aA}$ & $82,3 \mathrm{aB}$ & $53,0 \mathrm{aC}$ & $8,3 \mathrm{aD}$ \\
\hline flumioxazin & 0,050 & $4,7 \mathrm{cA}$ & $0,0 \mathrm{dA}$ & $0,0 \mathrm{bA}$ & $0,0 \mathrm{aA}$ \\
\hline $\mathrm{CV} \%$ & \multicolumn{5}{|c|}{ CV\% coluna: 33,22 e CV\% linha: 23,55} \\
\hline DMS & \multicolumn{5}{|c|}{ DMS coluna: 11,49 e DMS linha: 8,54} \\
\hline
\end{tabular}

Médias seguidas de mesma letra, minúscula na coluna e maiúscula na linha, não diferem pelo teste de Tukey a 5\% de probabilidade. DAA: dias após a aplicação. 
quando cultivado aos 120 DAA, o milheto sofreu redução de $39 \%$ no acúmulo de matéria seca da parte aérea das plantas, evidenciando a grande sensibilidade da espécie a esse herbicida. Szmigielski et al. (2009) observaram efeitos negativos desse herbicida em plantas de beterraba por um período de 302 dias, evidenciando a necessidade de maior intervalo de segurança entre a aplicação de sulfentrazone e a semeadura de milheto. Com a aplicação de flumioxazin, observaram-se efeitos significativos em cultivos inferiores a 80 DAA, porém de baixa magnitude.

Embora imazaquin e diclosulam tenham proporcionado menores danos sobre o acúmulo de massa seca da parte aérea quando comparados ao sulfentrazone, a persistência de ambos os herbicidas ocorreu até 120 DAA com a utilização do bioindicador milheto (híbrido ADR-7010), em campo. Aplicando imazaquin, obteve-se redução de $1,5 \%$ na massa seca, quando o milheto foi semeado aos 120 DAA; contudo, em relação ao diclosulam, a redução chegou a 5,8\%. Ulbrich et al. (1998) não constataram efeitos negativos sobre o acúmulo de massa seca em plantas de milho semeadas 120 DAA após a utilização de $120 \mathrm{~g} \mathrm{ha}^{-1}$ de imazaquin. Comparando as equações ajustadas (Tabela 2), observa-se que o efeito sobre a redução no acúmulo de massa seca foi semelhante estatisticamente para imazaquin e diclosulam. Todavia, nos demais tratamentos, todas as comparações foram significativas, indicando, por exemplo, que o sulfentrazone apresentou maior potencial negativo que os demais herbicidas, segundo o teste de comparação dos coeficientes angulares das equações previsto por Snedecor \& Cochran (1989). Ressalta-se a importância do planejamento na utilização de herbicidas de longa persistência, fato que repercute diretamente sobre o acúmulo de matéria seca, podendo representar um fator negativo no cultivo de milheto visando à produção de forragem ou de palhada para o sistema de plantio direto.

A variável-resposta altura de plantas seguiu a mesma tendência das demais já discriminadas; a utilização de sulfentrazone apresentou maior potencial supressor sobre plantas de milheto em semeadura realizada no tempo zero (Figura 2B). Observa-se que a redução na altura das plantas apresentou-se de forma inversamente proporcional ao intervalo de tempo utilizado para a semeadura da cultura. Apesar disso, mesmo quando semeado aos 120 DAA, a presença do sulfentrazone no solo causou redução de $27,9 \%$ em relação à testemunha, evidenciando novamente a persistência do herbicida, assim como a sensibilidade da espécie ou do híbrido utilizado. Nos demais herbicidas, a tendência de recuperação dos efeitos da intoxicação se tornou mais evidente nas semeaduras com maior intervalo de tempo entre a aplicação e a semeadura da espécie cultivada. A atividade residual dos herbicidas imazaquin e diclosulam não foi suficiente a ponto de interferir na altura das plantas de milheto semeado aos 120 DAA.
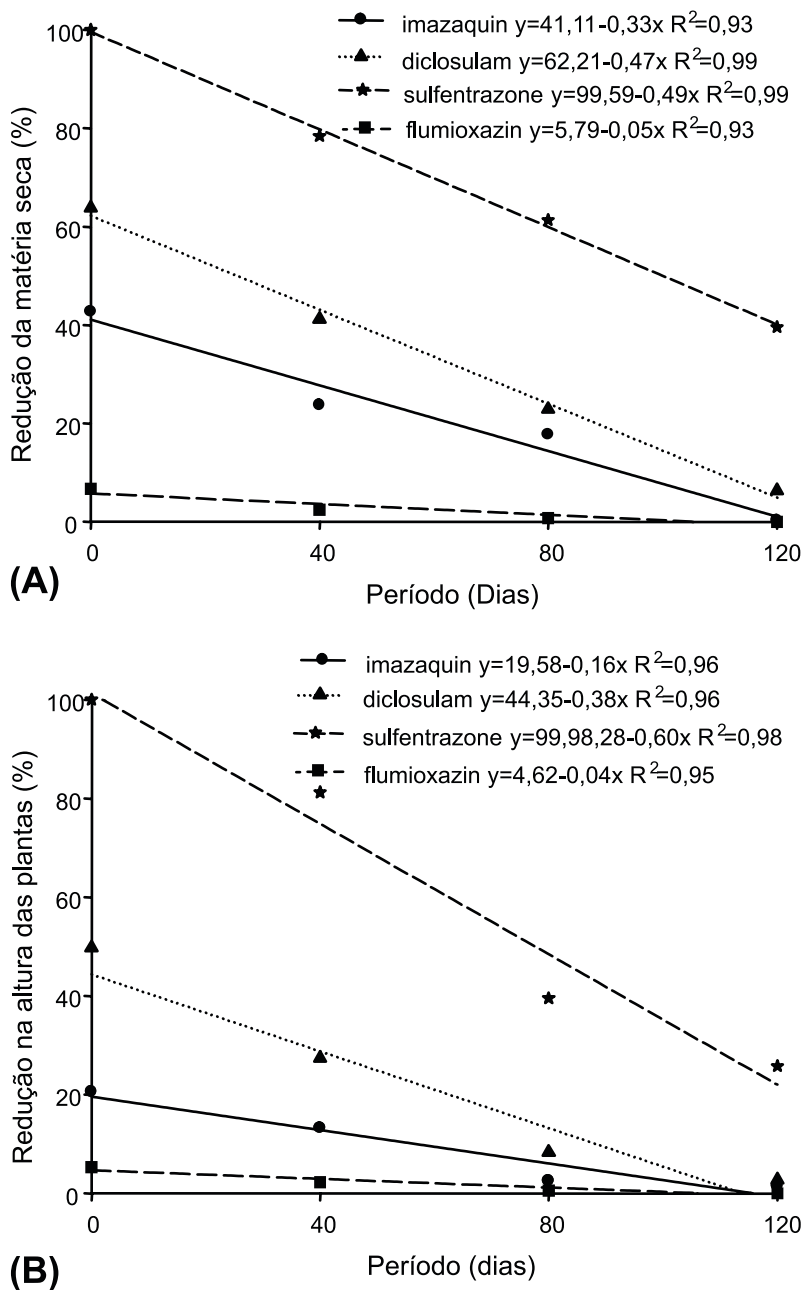

Figura 2 - Redução da massa da matéria seca da parte aérea (A) e da altura das plantas de milheto (B), cultivadas em solo após a aplicação de herbicidas na cultura da soja, em diferentes épocas de semeadura. 
Tabela 2 - Equações de regressão dos herbicidas imazaquin (IM), diclosulam (DI), sulfentrazone (SU) e flumioxazin (FL) no período de cultivo do milheto, em função da variável analisada

\begin{tabular}{|c|c|c|c|c|c|}
\hline \multirow{3}{*}{ Herbicida } & \multicolumn{5}{|c|}{ Variáv el analisada } \\
\hline & \multicolumn{2}{|c|}{ Intoxicação } & \multirow{2}{*}{ Altura de planta } & \multirow{2}{*}{ Matéria seca } & \multirow{2}{*}{ Rendimento } \\
\hline & $7 \mathrm{DAE}$ & $28 \mathrm{DAE}$ & & & \\
\hline IM vs DI & $\mathrm{ns}$ & $\mathrm{ns}$ & * & $\mathrm{ns}$ & $\mathrm{ns}$ \\
\hline IM vs SU & $* *$ & $* *$ & $* *$ & $* *$ & $* *$ \\
\hline IM vs FL & $* *$ & $* *$ & ** & $* *$ & $* *$ \\
\hline DI vs SU & $* *$ & $* *$ & $* *$ & $* *$ & $* *$ \\
\hline DI vs FL & ** & $* *$ & $* *$ & $* *$ & $* *$ \\
\hline SU vs FL & $* *$ & $* *$ & $* *$ & $* *$ & $* *$ \\
\hline
\end{tabular}

** e *: significativo a 1 e $5 \%$ pelo teste de comparação de modelos de Snedecor \& Cochran; ns: não significativo. DAE: dias após a emergência.

Mesmo por apresentar o mesmo mecanismo de ação do sulfentrazone, a atividade residual de flumioxazin foi menos intensa, sem efeitos aparentes sobre a altura das plantas de milheto cultivadas 80 dias após sua aplicação (DAA) (Figura 2B). É importante frisar que a altura de planta é um fator preponderante no processo de colheita dos grãos, já que na região dos cerrados essa espécie é colhida mecanicamente.

A intoxicação causada pelo efeito residual dos herbicidas proporcionou reduções significativas no rendimento de grãos da cultura (Figura 3). Dentro do intervalo de tempo estudado, as reduções foram mais acentuadas com a utilização de sulfentrazone, diclosulam e imazaquin, que proporcionaram 99,3, 89,6 e $78,0 \%$, respectivamente, na semeadura realizada imediatamente após a aplicação desses herbicidas no solo (tempo zero). A bioatividade dos herbicidas foi diminuindo gradativamente conforme se aumentou o intervalo entre a aplicação e a semeadura do milheto. Aos 120 DAA, redução mais severa foi causada pelos resíduos do sulfentrazone $(35,7 \%)$, indicando que o intervalo de tempo estudado não foi suficiente para que a dissipação do herbicida no ambiente não causasse danos ao rendimento da cultura. Além disso, esse efeito foi significativamente superior ao dos demais tratamentos (Tabela 2). Semeando o milheto aos 159 dias após a aplicação de $600 \mathrm{~g} \mathrm{ha}^{-1}$ de sulfentrazone, Blanco \& Velini (2005) observaram redução de $27 \%$ no rendimento dessa cultura. Segundo Christopher et al. (2004), a persistência do sulfentrazone no solo pode perdurar de um ano para o outro, a ponto de prejudicar a cultura do algodão em rotação com a soja. Dessa forma, torna-se importante o planejamento de utilização desse herbicida, que é uma importante ferramenta no manejo de plantas daninhas na cultura da soja e da cana-de-açúcar.

Apesar da ligeira redução dos efeitos supressores apresentados pelo diclosulam sobre a cultura do milheto (Figura 3), observase que a persistência desse herbicida no solo ocasionou redução de apenas $1,2 \%$ no rendimento da cultura, em semeadura realizada após a colheita da soja de ciclo precoce

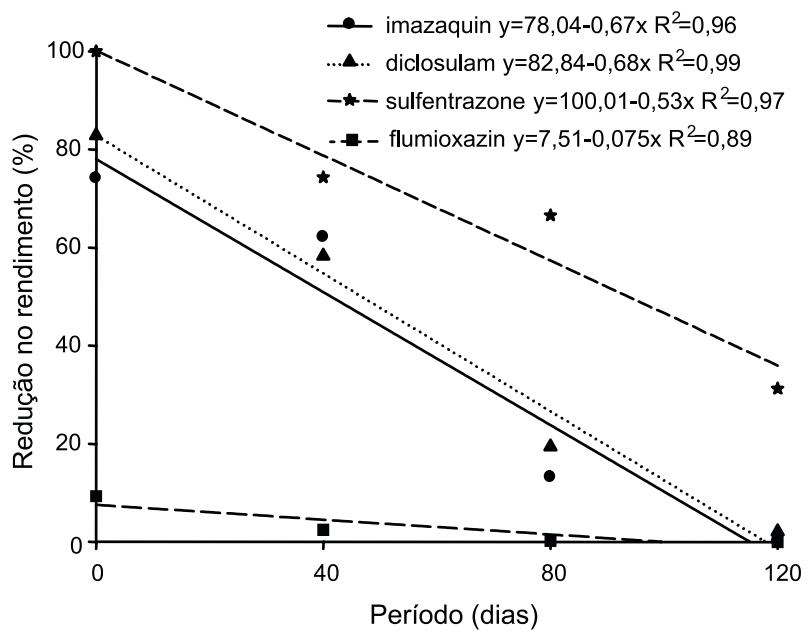

Figura 3 - Percentual de redução do rendimento de grãos da cultura do milheto, cultivado em solo após a aplicação de herbicidas na cultura da soja, em diferentes épocas de semeadura.

Planta Daninha, Viçosa-MG, v. 29, n. 2, p. 437-445, 2011 
(120 DAA). Embora tenha ocasionado essa pequena redução, os efeitos apresentados por diclosulam foram semelhantes aos observados para imazaquin (Tabela 2). Esses efeitos não foram observados por Artuzi \& Contiero (2006) na cultura do milho. Apesar de Lavorenti et al. (2003) considerarem o diclosulam um herbicida de baixa persistência, apesar das diferentes condições edafoclimáticas, é possivel que haja diferenças de sensibilidade entre espécies e até mesmo entre cultivares à presença desse herbicida no solo.

Embora o imazaquin tenha apresentado redução significativa no rendimento do milheto até o período de $80 \mathrm{DAA}$, não se observou nenhuma injúria causada pelo herbicida aos 120 DAA, mostrando que o cultivo de milheto após a colheita da soja onde foi utilizado imazaquin pode ser uma opção segura na safrinha, mas deve ser validada em áreas que apresentem diferentes tipos de solo e de precipitação pluvial. Gazziero et al. (1997), Ulbrich et al. (1998) e Artuzi \& Contiero (2006) não constataram efeitos do imazaquin utilizado em dose comercial sobre a cultura do milho cultivado em período superior a 120 DAA.

Com base nos resultados, foi possivel concluir que a cultura do milheto apresentou elevada sensibilidade à atividade residual do herbicida sulfentrazone, mesmo quando cultivada após a colheita da soja. A atividade residual dos herbicidas flumioxazin, imazaquin e diclosulam não foi suficiente para afetar negativamente o rendimento do milheto cultivado em sucessão à soja. Todavia, diclosulam e imazaquin apresentam significativo potencial de ocasionar efeitos negativos sobre a produção de grãos, forragem ou mesmo palhada no sistema de plantio direto, caso a semeadura do milheto ocorra em intervalo menor que 120 dias após a aplicação desses herbicidas.

\section{LITERATURA CITADA}

ALISTER, C. et al. Dissipation and movement of flumioxazin in soil at four field sites in Chile. Pest Manag. Sci., v. 64, n. 4, p. 579-583, 2008.

ARTUZI, J. P.; CONTIERO, R. L. Herbicidas aplicados na soja e produtividade do milho em sucessão. Pesq. Agropec. Bras., v. 41, n. 7, p. 1119-1123, 2006.

Planta Daninha, Viçosa-MG, v. 29, n. 2, p. 437-445, 2011
BAUGHMAN, T. A.; SHAW, D. R. Effect of wetting/drying cycles on dissipation patterns of bioavailable imazaquin. Weed Sci., v. 44, n. 2, p. 380-382, 1996.

BLANCO, F. M. G.; VELINI, E. D. Persistência do herbicida sulfentrazone em solo cultivado com soja e seu efeito em culturas sucedâneas. Planta Daninha, v. 23, n. 4, p. 693-700, 2005.

BRIGHENTI, A. M. et al. Persistência e fitotoxicidade do herbicida atrazine aplicado na cultura do milho sobre a cultura do girassol em sucessão. Planta Daninha, v. 20, n. 2, p. 291-297, 2002.

CHRISTOPHER, L. M. et al. Sulfentrazone persistence in southern soils: bioavailable concentration and effect on a rotational cotton crop. Weed Technol., v. 18, n. 2 , p. 346-352, 2004.

COBUCCI, T.; PORTELA, C. M. O. Seletividade de herbicidas aplicados em diferentes estádios de desenvolvimento da cultura do arroz de terras altas. Planta Daninha, v. 19, n. 3, p. 359-366, 2001.

DAN, H. A. et al. Seletividade do herbicida tembotrione a cultura do milheto. Planta Daninha, v. 28, n. 4, p.793-799, 2010 .

FERRELL, J. A. et al. Sorption and desorption of flumioxazin to soil, clay minerals and ion-exchange resin. Pest Manag. Sci., v. 61, n. 1, p. 40-46, 2005.

GAZZIERO, D. L. P. et al. Persistência dos herbicidas imazaquim e imazethapyr no solo e os efeitos sobre plantas de milho e pepino. Planta Daninha, v. 15, n. 2, p. 162-169, 1997.

LAVORENTI, A. et al. Comportamento do diclosulam em amostras de um Latossolo Vermelho distroférrico sob plantio direto e convencional. R. Bras. Ci. Solo, v. 27, n. 2, p. 183-190, 2003.

LIMA, R. O. et al. Comportamento do herbicida flumioxazin em solo com diferentes doses de calcário. R. Ceres, v. 46, n. 2, p. 607-613, 1999.

REDDY, K. N.; LOCKE, M. A. Sulfentrazone sorption, and mineralization in soil from two tillage systems. Weed Sci., v. 46, n. 1, p. 494-500, 1998

SILVA, A. A. et al. Avaliação da atividade residual no solo de imazaquim e trifluralin através de bioensaios com milho. Acta Sci., v. 20, n. 3, p. 291-295, 1998

SNEDECOR, G. W.; COCHRAN, W. G. Statistical methods 8.ed. Ames: Iowa State University Press, 1989. 503 p. 
SZMIGIELSKI, A. M. et al. Development of a laboratory bioassay and effect of soil properties on sulfentrazone phytotoxicity in soil. Weed Technol., v. 23, n. 5, p. 486-491, 2009.

TORRES, J. L. R. et al. Produção de fitomassa por plantas de cobertura e mineralização de seus resíduos em plantio direto.

Pesq. Agropec. Bras., v. 43, n. 1, p. 421-428, 2008.

ULBRICH, A. V. et al. Efeito residual dos herbicidas imazaquim e imazethapyr, aplicados na soja, sobre o milho safrinha. Planta Daninha, v. 16, n. 1, p. 137-147, 1998
ULBRICH, A. V. et al. Persistence and carryover effect of imazapic and imazapyr in Brazilian cropping systems. Weed Technol., v. 19, n. 4, p. 986-991, 2005

YODER, R. N. et al. Aerobic metabolism of diclosulam on U.S. and South American soils. J. Agric. Food Chem., v. 48, n. 1, p. 4335-4340, 2000.

WILCUT, J. W. et al. Virginia market-type peanut (Arachis hypogaea) cultivar tolerance and yield response to flumioxazin pre-emergence. Weed Technol., v. 17, n. 4, p. $137-140,2003$. 